\title{
Ubiquinol reduces gamma glutamyltransferase as a marker of oxidative stress in humans
}

\author{
Simone Onur ${ }^{1}$, Petra Niklowitz ${ }^{2}$, Gunnar Jacobs ${ }^{3}$, Ute Nöthlings ${ }^{4}$, Wolfgang Lieb ${ }^{3}$, Thomas Menke ${ }^{2}$ \\ and Frank Döring ${ }^{1 *}$
}

\begin{abstract}
Background: The reduced form of Coenzyme $\mathrm{Q}_{10}\left(\mathrm{CoQ}_{10}\right)$, ubiquinol $\left(\mathrm{Q}_{10} \mathrm{H}_{2}\right)$, serves as a potent antioxidant in mitochondria and lipid membranes. There is evidence that $\mathrm{Q}_{10} \mathrm{H}_{2}$ protects against oxidative events in lipids, proteins and DNA. Serum gamma-glutamyltransferase (GGT) activity is associated with cardiovascular diseases. In a physiological range, activity of GGT is a potential early and sensitive marker of inflammation and oxidative stress. In this study, we first examined the relationship between $\mathrm{CoQ}_{10}$ status and serum GGT activity in 416 healthy participants between 19 and 62 years of age in a cross-sectional study (cohort I). In the second step, 53 healthy males (21-48 years of age; cohort II) underwent a 14-day $\mathrm{Q}_{10} \mathrm{H}_{2}$ supplementation (150 mg/d) to evaluate the effect of $\mathrm{Q}_{10} \mathrm{H}_{2}$ supplementation on serum GGT activity and GGT1 gene expression.

Findings: There was a strong positive association between $\mathrm{CoQ}_{10}$ status and serum GGT activity in cohort I. However, a gender-specific examination revealed differences between male and female volunteers regarding the association between $\mathrm{CoQ}_{10}$ status and serum GGT activity. $\mathrm{Q}_{10} \mathrm{H}_{2}$ supplementation (cohort II) caused a significant decrease in serum GGT activity from $T_{0}$ to $T_{14}(p<0.001)$. GGT1 mRNA levels declined 1.49-fold after $\mathrm{Q}_{10} \mathrm{H}_{2}$ supplementation. Of note, other liver enzymes (i.e., aspartate aminotransferase, AST) were not affected by $\mathrm{Q}_{10} \mathrm{H}_{2}$ supplementation.
\end{abstract}

Conclusions: $\mathrm{CoQ}_{10}$ level is positively associated with serum GGT activity. Supplementation with $\mathrm{Q}_{10} \mathrm{H}_{2}$ reduces serum GGT activity. This effect might be caused by gene expression. Overall, we provide preliminary evidence that higher $\mathrm{Q}_{10} \mathrm{H}_{2}$ levels improve oxidative stress via reduction of serum GGT activity in humans.

Trial registration: Current Controlled Trials ISRCTN26780329.

Keywords: Coenzyme $\mathrm{Q}_{10}$, Ubiquinol, Gene expression, Supplementation study, Liver enzymes, Oxidative stress, Antioxidants

\section{Background}

Coenzyme $\mathrm{Q}_{10}\left(\mathrm{CoQ}_{10}\right)$ is a redox molecule that is present in the membranes of almost all human tissues [1]. $\mathrm{CoQ}_{10}$ is a lipophilic molecule that is synthesized within the mitochondrial inner membrane and is essential for the respiratory transport chain. As an antioxidant in cell membranes, $\mathrm{CoQ}_{10}$ is important for the maintenance of the cellular redox homeostasis [2]. Furthermore, $\mathrm{CoQ}_{10}$ is necessary for pyrimidine biosynthesis while also being a cofactor for uncoupling proteins [3]. It has also been identified as a

\footnotetext{
*Correspondence: sek@molprev.uni-kiel.de

${ }^{1}$ Institute of Human Nutrition and Food Science, Division of Molecular Prevention, Christian Albrechts University Kiel, Heinrich-Hecht-Platz 10, 24118 Kiel, Germany

Full list of author information is available at the end of the article
}

modulator of gene expression [4-6], inflammatory processes [7-9] and apoptosis [10,11]. The reduced form of $\mathrm{CoQ}_{10}$, ubiquinol $\left(\mathrm{Q}_{10} \mathrm{H}_{2}\right)$, serves as a potent antioxidant in mitochondria and lipid membranes as well as a regenerator of other lipid soluble antioxidants [12]. In recent years, there has been growing evidence of the protective role of $\mathrm{Q}_{10} \mathrm{H}_{2}$ in oxidative events in lipids, proteins and DNA, a concept known as oxidative stress [13,14].

The liver enzyme gamma glutamyltransferase (GGT) is located at the outer surface of the plasma membrane where it facilitates the synthesis of the antioxidant glutathione (GSH) [15]. GGT initiates the degradation of extracellular GSH by hydrolyzing the $\gamma$-glutamyl-cysteine bond in GSH [16]. The regulation of GGT is complex. Human GGT is 
encoded by a multi-gene family consisting of at least seven genes. One of these genes, GGT1, encodes for the active enzyme present in human tissues [17]. Serum GGT has long been regarded as a marker for excessive alcohol consumption or liver disturbances in clinical practice [18]. However, it has recently been shown that serum GGT is also a marker for the development of cardiovascular disease, hypertension, stroke and type 2 diabetes mellitus and their complications independent from alcohol consumption [19-22]. Further studies provide evidence that serum GGT activity is a potential early and sensitive marker of inflammation and oxidative stress [23-25]. Of note, this effect was only found in the physiological range of GGT activity.

It is known that oxidative stress can be attenuated by $\mathrm{Q}_{10} \mathrm{H}_{2}[13,14]$. Because serum GGT is a putative marker of oxidative stress, we examined (i) the relationship between $\mathrm{CoQ}_{10}$ status and serum GGT activity in a sample of 416 healthy volunteers (cohort I) and (ii) the effect of $\mathrm{Q}_{10} \mathrm{H}_{2}$ supplementation on serum GGT activity and GGT1 gene expression in an intervention cohort of 53 healthy male volunteers (cohort II).

\section{Methods}

Study populations

\section{Cohort I - cross-sectional study}

The study sample was part of the PopGen control cohort. The original study design is described elsewhere [26]. The study population consisted of 416 healthy blood donors between 19 and 62 years old with a mean body mass index (BMI) of $26.1 \mathrm{~kg} / \mathrm{m}^{2}$ (standard deviation, $4.7 \mathrm{~kg} / \mathrm{m}^{2}$ ). A total of $53 \%$ were males. All study participants were phenotyped with respect to anthropometric, cardiovascular and metabolic traits in a standardized fashion (details below). Blood samples were taken after an overnight fast and immediately centrifuged. Serum samples were stored at $-80^{\circ} \mathrm{C}$ until $\mathrm{CoQ}_{10}$ was analyzed. The participants had no history of gastrointestinal, hepatic, cardiovascular or renal diseases; maintained usual nutrition habits; and were non-smokers or occasional smokers. The study was approved by the ethics committee of the Medical Faculty of Kiel University and was consistent with the Helsinki Declaration. All volunteers gave written informed consent. Recruitment of study probands as well as data and biosample collection were performed using the PopGen biobank, Kiel, Germany.

\section{Cohort II - supplementation study}

The sample characteristics and study design have been described previously [27]. Briefly: 53 healthy male volunteers between 21 and 48 years of age received $150 \mathrm{mg}$ of the reduced form of $\mathrm{CoQ}_{10}\left(\mathrm{Q}_{10} \mathrm{H}_{2}\right.$, ubiquinol, KANEKA Corporation, Japan) daily in the form of three capsules à $50 \mathrm{mg} \mathrm{Q}_{10} \mathrm{H}_{2}$ taken with each main meal (breakfast, lunch and dinner) for 14 days. Fasting blood samples were taken before $\left(\mathrm{T}_{0}\right)$ and after $\left(\mathrm{T}_{14}\right)$ supplementation. The participants had an average BMI of $24.1 \pm 2.5 \mathrm{~kg} / \mathrm{m}^{2}$; had no history of gastrointestinal, hepatic, cardiovascular or renal diseases; maintained usual nutrition habits; and were non-smokers or occasional smokers. The study was approved by the ethics committee of the Medical Faculty of Kiel University, Germany, and was consistent with the Helsinki Declaration. All volunteers gave written informed consent.

\section{$\mathrm{CoQ}_{10}$ analysis}

$\mathrm{CoQ}_{10}$ analysis was based on the method of highpressure liquid chromatography (HPLC) with electrochemical detection and internal standardization using ubihydroquinone- 9 and ubiquinone- 9 as standards, as described elsewhere [28]. $100 \mu \mathrm{L}$ plasma aliquots were used in both cohorts to perform robust HPLC analysis with repeats, when indicated.

\section{Anthropometric measurements}

Body weight was measured in underwear on a manual scale to the nearest $100 \mathrm{~g}$ (Seca, Hamburg, Germany). Height was measured without shoes on a stadiometer (Seca, Hamburg, Germany) to the nearest $0.5 \mathrm{~cm}$.

\section{Clinical parameters, metabolic parameters and gene expression}

Blood pressure measurements were obtained while the subject was in a seated position, using a standard manual sphygmomanometer. A fasting venous blood sample was obtained from all study participants and analyzed following standard procedures. Briefly, blood glucose was analyzed using a hexokinase method (Gluco-quant, Roche Diagnostics, Mannheim, Germany). Cholesterol and triacylglycerol concentrations were measured enzymatically by hydrolyzing cholesterol ester and triacylglycerol to cholesterol and glycerol, respectively. HDL cholesterol (HDL-C) was measured in the supernatant after precipitation of lipoproteins (kits and standards by Konelab Corporation, Espoo, Finland). The liver enzymes gamma glutamyltransferase (GGT) and aspartate aminotransferase (AST) were analyzed according to the recommendations of the International Federation of Clinical Chemistry (IFCC) from 1983 (confirmed and extended in 2002), including optimization of substrate concentrations and employment of $\mathrm{NaOH}$, glycylglycine buffer and sample start. Plasma C-reactive protein (CRP) concentrations were measured using a latex enhanced nephelometric assay run on a BN II hematology analyzer (Dade Behring, Marburg, Germany). Microarray experiments using the Affymetrix human genome U133 plus $2.0 \mathrm{GeneChip}^{\circ}$ were performed as previously described [5] with RNA samples from CD14-positive monocytes obtained from three volunteers before $\left(\mathrm{T}_{0}\right)$ and after $\left(\mathrm{T}_{14}\right)$ supplementation with ubiquinol. 


\section{Statistics}

Statistical analyses were performed with SPSS (Statistical Package for the Social Sciences) 20.0 software (SPSS GmbH Software, München, Germany). Before statistical analysis, normal distribution of the parameters was tested. Genderrelated differences in anthropometric and metabolic parameters and differences between subjects with normal and elevated GGT activity were analyzed using a nonparametric Mann-Whitney $U$-test. Differences from supplementation regarding two time-points $\left(\mathrm{T}_{0}\right.$ vs. $\left.\mathrm{T}_{14}\right)$ were tested using a paired Student's $t$-test. The level of statistical significance was set at $\mathrm{p}<0.05$.

\section{Findings}

\section{Study population - cohort I}

We examined 416 healthy volunteers in a cross-sectional study. As shown in Figure 1, more than $90 \%$ of the study population had normal activity of serum GGT $(<50 / 40 \mathrm{U} / \mathrm{l}$ male/female), whereas $9.1 \%(\mathrm{n}=21)$ of male and $6.1 \%$ $(\mathrm{n}=12)$ of female volunteers had increased serum GGT activity. Because serum GGT activity is postulated to be a marker of oxidative stress in its normal range, study subjects with elevated serum activity of GGT were excluded.

The characteristics of cohort I are depicted in Table 1. Study subjects were healthy but slightly overweight (mean BMI $26.2 \pm 4.7 \mathrm{~kg} / \mathrm{m}^{2}$ ) with a mean age of 40.0 years. On average, values of $\mathrm{CoQ}_{10}$ status and proinflammatory CRP were in a normal range. Components of metabolic syndrome were below the thresholds

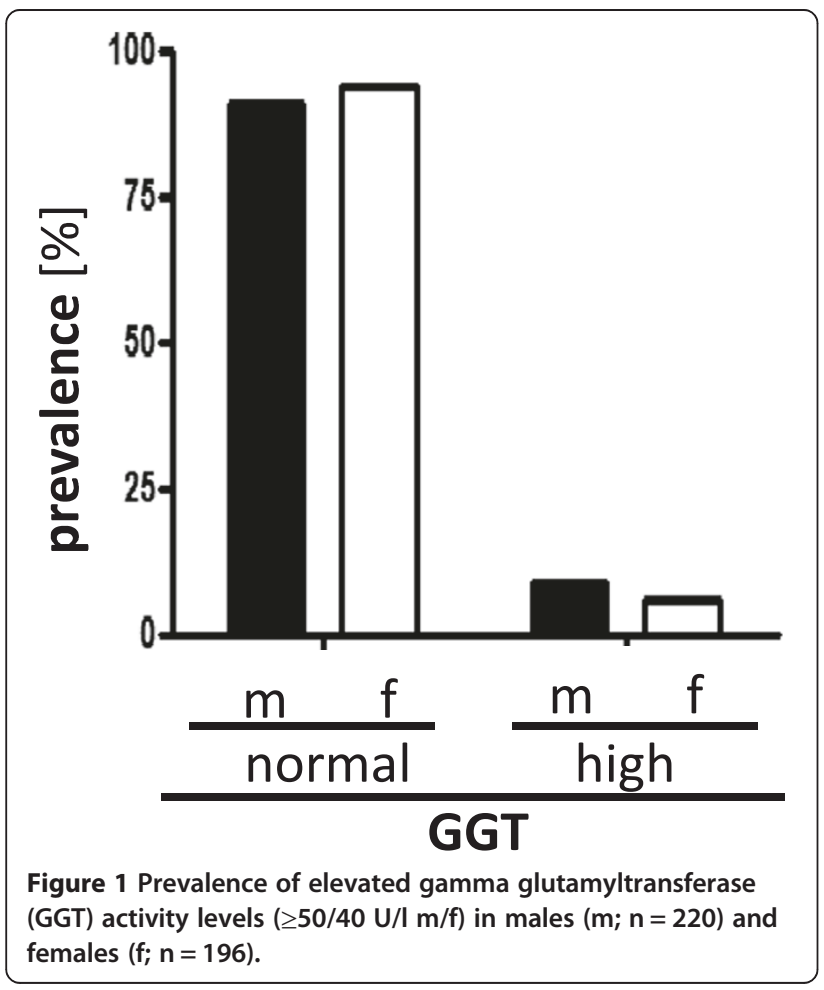

defined by the Adult Treatment Panel III (ATPIII). Gender-stratified analyses revealed significant differences between males and females. Compared to women, men had higher $\mathrm{BMI}$, total $\mathrm{CoQ}_{10}$, ubiquinol, GGT activity, blood pressure, triglycerides, total and LDL-cholesterol and glucose, whereas women had higher CRP- and HDL-cholesterol levels than men. Additionally, female volunteers tended to have a higher $\mathrm{CoQ}_{10}$-redox state (\% oxidized $\mathrm{CoQ}_{10}$ in total $\mathrm{CoQ}_{10} ; \mathrm{p}=0.054$ ) compared to males.

\section{$\mathrm{CoQ}_{10}$ is related to serum GGT activity by gender}

We conducted a correlation analysis to evaluate the relationship between $\mathrm{CoQ}_{10}$ status and serum GGT activity. As shown in Table 2, levels of total $\mathrm{CoQ}_{10}$, ubiquinol, ubiquinone (oxidized form of $\mathrm{CoQ}_{10}$; all $\mathrm{p}<0.001$ ) and redox state $(\mathrm{p}<0.05)$ were positively correlated with serum GGT activity in the whole study sample. Analyses conducted separately by gender revealed a stronger positive correlation between total $\mathrm{CoQ}_{10}$ level and serum GGT activity in men $(\mathrm{p}<0.001)$ than in women $(\mathrm{p}<$ 0.05). Additionally, the reduced form of $\mathrm{CoQ}_{10}$, ubiquinol, was positively associated with serum GGT activity $(\mathrm{p}<0.001)$ in men but not in women. In contrast, the oxidized form of $\mathrm{CoQ}_{10}$, ubiquinone, had a stronger positive correlation with serum GGT activity in women $(\mathrm{p}<0.001)$ than in men $(\mathrm{p}<0.01)$, and interestingly, there was a highly significant positive correlation between the redox state and serum GGT activity solely in women $(\mathrm{p}<0.001)$. These results are shown in Figure 2, which depicts the positive linear association between $\mathrm{CoQ}_{10}$ status and serum GGT activity in the whole population as well as in gender-specific sub-groups. With the exception of the $\mathrm{CoQ}_{10}$ redox state, all parameters of $\mathrm{CoQ}_{10}$ status were positively correlated with serum GGT activity. However, there were genderspecific differences. While the data from men showed a stronger positive relationship between levels of both total $\mathrm{CoQ}_{10}$ (Figure 2A) and ubiquinol (Figure 2B) and serum GGT activity compared with the relationship found in women, there was only a small gender-related difference in the $\mathrm{R}^{2}$ of ubiquinone and serum GGT activity (Figure $2 \mathrm{C}$ ). In addition, women but not men had a strong positive association between the redox state of $\mathrm{CoQ}_{10}$ and the activity of serum GGT activity (Figure 2D).

\section{$\mathrm{CoQ}_{10}$ is not associated with other liver-related enzymes (i.e., AST)}

To evaluate the specificity of the relationship between $\mathrm{CoQ}_{10}$ and GGT, we also performed a correlation analysis with the parameters of $\mathrm{CoQ}_{10}$ status and serum aspartate aminotransferase activity (AST). As shown in Table 3, there were no significant associations between $\mathrm{CoQ}_{10}$ status and serum AST activity. 
Table 1 Basic characteristics of cohort I (subsample of the popgen control cohort)

\begin{tabular}{|c|c|c|c|}
\hline & All $(n=383)$ & Males $(n=199)$ & Females $(n=184)$ \\
\hline Age [years] & $40.0 \pm 10.9$ & $40.5 \pm 10.5$ & $38.7 \pm 11.2$ \\
\hline Body mass index $\left[\mathrm{kg} / \mathrm{m}^{2}\right]$ & $26.2 \pm 4.7$ & $26.2 \pm 3.9$ & $25.7 \pm 5.2^{* *}$ \\
\hline $\mathrm{CoQ}_{10}[\mu \mathrm{mol} / \mathrm{l}]$ & $0.94 \pm 0.34$ & $0.96 \pm 0.36$ & $0.87 \pm 0.29^{*}$ \\
\hline Ubiquinol $[\mu \mathrm{mol} / \mathrm{l}]$ & $0.12 \pm 0.05$ & $0.12 \pm 0.04$ & $0.11 \pm 0.04$ \\
\hline Ubiquinone $[\mu \mathrm{mol} / \mathrm{l}]$ & $0.82 \pm 0.30$ & $0.84 \pm 0.33$ & $0.76 \pm 0.25^{*}$ \\
\hline $\mathrm{CoQ}_{10}$ redox state [\%] & $12.5 \pm 2.6$ & $12.2 \pm 2.5$ & $12.7 \pm 2.7$ \\
\hline Gamma GT [U/I] & $18.8 \pm 8.4$ & $22.5 \pm 8.3$ & $14.7 \pm 6.3^{* * *}$ \\
\hline C-reactive protein[mg/l] & $2.24 \pm 3.36$ & $1.58 \pm 1.92$ & $2.47 \pm 3.00^{* * *}$ \\
\hline Systolic BP [mm Hg] & $130 \pm 16$ & $134 \pm 15$ & $125 \pm 14^{* * *}$ \\
\hline Diastolic BP [mm Hg] & $78 \pm 9$ & $80 \pm 9$ & $75 \pm 8^{* * *}$ \\
\hline Triglycerides [mg/dl] & $121.9 \pm 73.3$ & $132.1 \pm 76.1$ & $100.5 \pm 50.3^{* * *}$ \\
\hline Cholesterol [mg/dl] & $193.3 \pm 35.7$ & $194.3 \pm 39.8$ & $190.3 \pm 28.8$ \\
\hline LDL-cholesterol [mg/dl] & $116.6 \pm 32.5$ & $122.6 \pm 34.7$ & $108.0 \pm 26.1^{* * *}$ \\
\hline HDL-cholesterol [mg/dl] & $62.1 \pm 16.7$ & $54.8 \pm 13.4$ & $71.1 \pm 16.1^{* * *}$ \\
\hline Glucose [mg/dl] & $92.5 \pm 10.7$ & $94.1 \pm 11.3$ & $90.1 \pm 9.7^{* * *}$ \\
\hline
\end{tabular}

$\mathrm{CoQ}_{10}=$ Coenzyme $\mathrm{Q}_{10}$, Gamma $\mathrm{GT}=$ gamma glutamyltransferase; $\mathrm{BP}=$ blood pressure; $\mathrm{LDL}=$ low density lipoprotein, $\mathrm{HDL}=$ high density lipoprotein

Data are presented as mean $\pm \mathrm{SD}$; ${ }^{*} \mathrm{p}<0.05$; ${ }^{* *} \mathrm{p}<0.01$; ${ }^{* *} \mathrm{p}<0.001$ significant differences between sexes, Mann-Whitney U-test.

\section{$\mathrm{Q}_{10} \mathrm{H}_{2}$ Supplementation study - cohort II}

To examine whether $\mathrm{Q}_{10} \mathrm{H}_{2}$ supplementation influences the activity of GGT and AST, we re-analyzed our human intervention study [27]. Within this study, 53 healthy male volunteers were supplemented with $150 \mathrm{mg}$ ubiquinol per day for two weeks. Table 4 shows the basic characteristics of the study population (cohort II). The study subjects were between 21 and 48 years of age with a mean BMI of $24.1 \pm 2.5 \mathrm{~kg} / \mathrm{m}^{2}$. All parameters regarding $\mathrm{CoQ}_{10}$ status, CRP status as well as the parameters of metabolic syndrome defined by ATPIII were within a normal range.

To investigate the effects of $\mathrm{Q}_{10} \mathrm{H}_{2}$ supplementation, fasting blood samples were taken before $\left(\mathrm{T}_{0}\right)$ and after $\left(\mathrm{T}_{14}\right)$ supplementation with $\mathrm{Q}_{10} \mathrm{H}_{2}$. As described previously, plasma $\mathrm{CoQ}_{10}$ levels increased more than fourfold from $\mathrm{T}_{0}$ to $\mathrm{T}_{14}(0.96 \pm 0.31 \mathrm{pmol} / \mu \mathrm{l}$ to $4.60 \pm 1.55 \mathrm{pmol} /$ $\mu \mathrm{l}, \mathrm{p}<0.001$, data not shown) whereas the redox state decreased significantly from $7.47 \pm 0.97 \%$ to $5.95 \pm 0.91 \%$ ( $<<0.001$; data not shown) [27].
$\mathrm{Q}_{10} \mathrm{H}_{2}$ supplementation reduces serum $\mathrm{GGT}$ activity and mediates down regulation of GGT1 mRNA

Figure 3A shows a significant decrease of GGT activity from $\mathrm{T}_{0}$ to $\mathrm{T}_{14}(20.49 \pm 10.36 \mathrm{U} / \mathrm{l}$ to $17.79 \pm 7.68 \mathrm{U} / \mathrm{l}$; $\mathrm{p}<0.001)$. In contrast, we found no alteration of AST activity in response to $\mathrm{Q}_{10} \mathrm{H}_{2}$ supplementation (Figure $3 \mathrm{~B}$ ). To investigate whether the effect on GGT activity is also detectable on gene expression level, the mRNA steady state level of both GGT1 (GGT) and GOT2 (AST) were determined in CD14-positive monocytes of three subjects before and after $\mathrm{Q}_{10} \mathrm{H}_{2}$ supplementation. Indeed, we found that $\mathrm{Q}_{10} \mathrm{H}_{2}$ supplementation reduced the GGT1 mRNA level with a fold change of -1.49 (Figure 3C) and the GOT2 mRNA level with a fold change of -1.34 (Figure 3D).

\section{Discussion}

Association between $\mathrm{CoQ}_{10}$ status and serum GGT activity Highly elevated serum GGT is a well-known marker of alcohol consumption, alcoholic liver diseases, and cholestasis

Table 2 Correlation coefficients between Coenzyme $Q_{10}\left(C_{0} Q_{10}\right)$ status and gamma glutamyltransferase (GGT)

\begin{tabular}{llll}
\hline & \multicolumn{1}{c}{ GGT } \\
\cline { 2 - 4 } & All $(\mathbf{n = 3 8 3 )}$ & Males $(\mathbf{n = 2 2 0})$ & Females $(\mathbf{n = 1 9 6 )}$ \\
\hline $\mathrm{CoQ}_{10}[\mu \mathrm{mol} / \mathrm{l}]$ & $0.276^{* * *}$ & $0.290^{* * *}$ & $0.161^{*}$ \\
Ubiquinol $[\mu \mathrm{mol} / \mathrm{l}]$ & $0.258^{* * *}$ & $0.267^{* * *}$ & 0.137 \\
Ubiquinone $[\mu \mathrm{mol} / \mathrm{l}]$ & $0.240^{* * *}$ & $0.217^{* *}$ & $0.290^{* * *}$ \\
$\mathrm{CoQ}_{10}$ redox state $[\%]$ & $0.105^{*}$ & 0.089 & $0.273^{* * *}$ \\
\hline
\end{tabular}

${ }^{*} \mathrm{p}<0.05 ;{ }^{* *} \mathrm{p}<0.01,{ }^{* * *} \mathrm{p}<0.001$. 


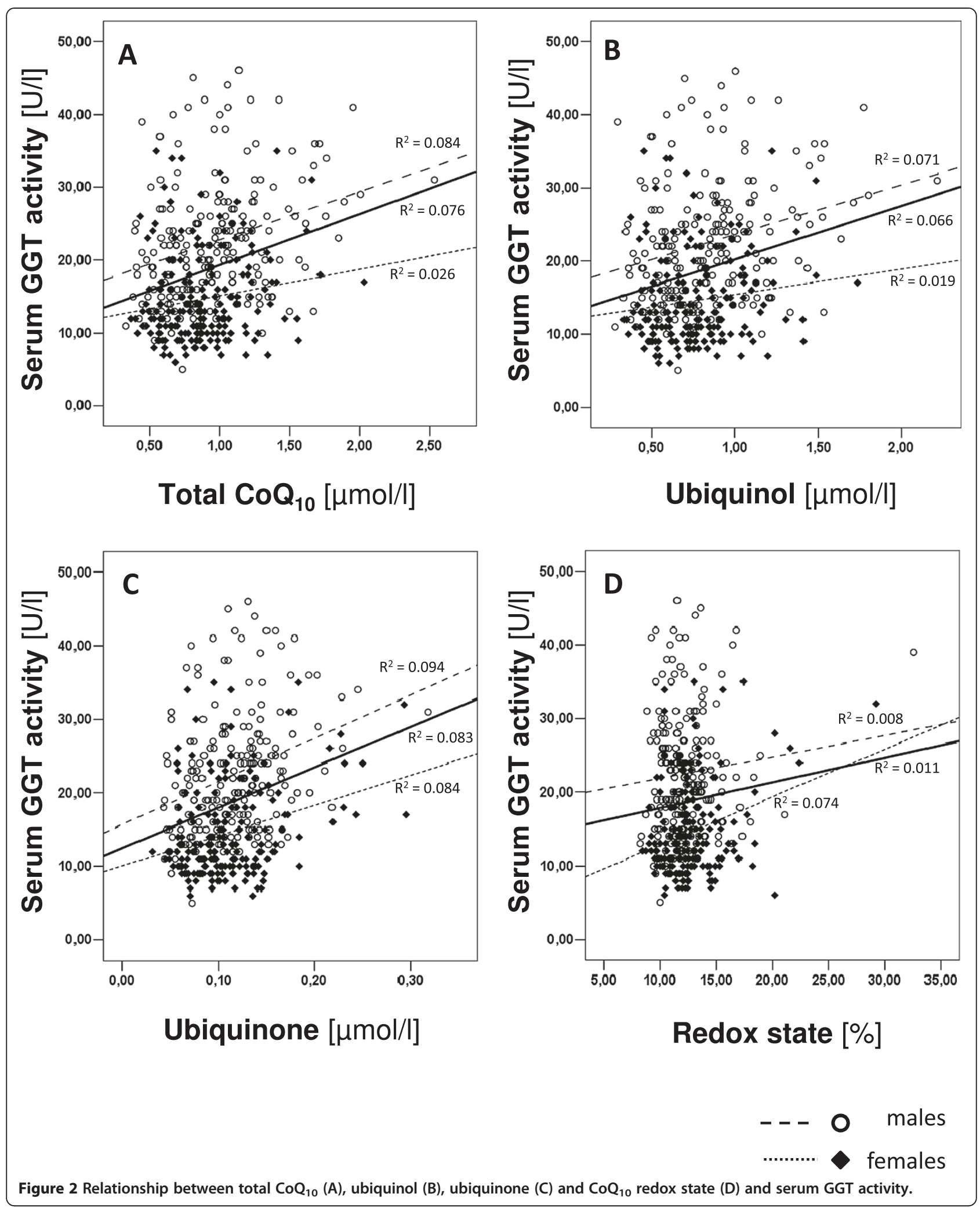


Table 3 Correlation coefficients of Coenzyme $Q_{10}\left(C_{0} Q_{10}\right)$ status and aspartate aminotransferase (AST)

\begin{tabular}{llll}
\hline & & \multicolumn{1}{c}{ AST } & Females $(\mathbf{n}=\mathbf{1 8 4})$ \\
\cline { 2 - 4 } & All $(\mathbf{n}=\mathbf{3 8 3})$ & Males $(\mathbf{n}=\mathbf{1 9 9})$ & 0.044 \\
Ubiquinol $[\mu \mathrm{mol} / \mathrm{l}]$ & 0.086 & 0.093 & 0.062 \\
Ubiquinone $[\mu \mathrm{mol} / \mathrm{l}]$ & 0.097 & 0.099 & 0.003 \\
$\mathrm{CoQ}_{10}$ redox state $[\%]$ & 0.028 & 0.042 & -0.049 \\
\hline
\end{tabular}

[18]. Furthermore, several researchers have postulated that serum GGT activity, in its normal range, is a potential marker of oxidative stress [23-25]. It was shown in a longitudinal study that low circulating concentrations of several antioxidants (i.e., tocopherols, carotenoids) inversely predicted serum GGT concentrations ten years later [29]. Because $\mathrm{CoQ}_{10}$ is a known antioxidant, one would expect decreased levels of antioxidative $\mathrm{CoQ}_{10}$ or ubiquinol in the presence of high serum GGT activity. In the present study, there was a strong positive relationship between serum GGT activity and total $\mathrm{CoQ}_{10}$, ubiquinol and ubiquinone in study subjects with normal serum GGT activity. As we examined the relationship between $\mathrm{CoQ}_{10}$ status and serum GGT activity in a cross-sectional study, we were only able to examine one time point. Therefore, longitudinal studies should be conducted to elucidate the long-term relationship of serum $\mathrm{CoQ}_{10}$ and serum GGT activity. Nevertheless, it is possible that serum GGT may be an activator of the antioxidative system in humans exposed to oxidative stress. If so, $\mathrm{CoQ}_{10}$ might be the first antioxidant that is

Table 4 Basic characteristics of cohort II (supplementation study)

\begin{tabular}{|c|c|}
\hline & Males $(n=53)$ \\
\hline Age [years] & $30.1 \pm 6.7$ \\
\hline Body mass index $\left[\mathrm{kg} / \mathrm{m}^{2}\right]$ & $24.1 \pm 2.5$ \\
\hline $\mathrm{CoQ}_{10}[\mu \mathrm{mol} / \mathrm{l}]$ & $0.96 \pm 0.31$ \\
\hline Ubiquinol $[\mu \mathrm{mol} / \mathrm{l}]$ & $0.89 \pm 0.29$ \\
\hline Ubiquinone $[\mu \mathrm{mol} / \mathrm{l}]$ & $0.07 \pm 0.02$ \\
\hline $\mathrm{CoQ}_{10}$ redox state [\%] & $7.5 \pm 0.97$ \\
\hline Gamma GT [U/I] & $20.5 \pm 10.4$ \\
\hline C-reactive protein $[\mathrm{mg} / \mathrm{dl}]$ & $0.30 \pm 0.01$ \\
\hline systolic BP [mm Hg] & $127 \pm 12$ \\
\hline Diastolic BP [mm Hg] & $83 \pm 9$ \\
\hline Triglycerides [mg/dl] & $97.4 \pm 49.0$ \\
\hline Cholesterol [mg/dl] & $166.1 \pm 29.8$ \\
\hline LDL-cholesterol [mg/dl] & $95.5 \pm 28.9$ \\
\hline HDL-cholesterol [mg/dl] & $51.1 \pm 12.9$ \\
\hline Glucose [mg/dl] & $86.5 \pm 10.7$ \\
\hline
\end{tabular}

$\mathrm{CoQ}_{10}=$ Coenzyme $\mathrm{Q}_{10}$, Gamma GT = gamma glutamyltransferase; $\mathrm{BP}=$ blood pressure; $\mathrm{LDL}=$ low density lipoprotein, $\mathrm{HDL}=$ high density lipoprotein. Data are presented as mean \pm SD. synthesized or released due to elevated serum GGT activity. This hypothesis is supported by ideas from the CARDIA study. There, it was speculated that an increase of serum GGT might eventually minimize oxidative stress by facilitating antioxidative defense (i.e., GSH) [23].

In summary, there is a strong relationship between human $\mathrm{CoQ}_{10}$ status and serum GGT activity. However, further investigations are needed to elucidate the complex relationship between antioxidant $\mathrm{CoQ}_{10}$ and serum GGT as a potential marker of oxidative stress in more detail. For this purpose, additional specific and stable byproducts of oxidative damage to lipids, DNA or proteins in the blood should also be examined in future research.

\section{Gender-specific differences in the association between $\mathrm{CoQ}_{10}$ status and serum GGT activity}

It is known that higher $\mathrm{CoQ}_{10}$ levels as well as increased GGT activity are strongly associated with male gender $[20,30,31]$. This finding was confirmed in our study because men had higher levels of both $\mathrm{CoQ}_{10}$ and serum GGT activity than women. Additionally, this fact explains the gender-specific differences regarding the strength of the correlation between serum GGT activity and $\mathrm{CoQ}_{10}$ status in our study sample. The reasons for gender-related differences in $\mathrm{CoQ}_{10}$ levels and serum GGT activity are most likely physiologic and based on hormonal differences between the genders. It was previously shown in females that the use of oral contraceptives increased GGT activity level by 15 percent and pregnancy lowered GGT activity level by 25 percent, whereas the postmenopausal state was associated with a 7 percent increase in GGT activity [32]. Similar hormonal relationships have been shown for $\mathrm{CoQ}_{10}$ but in the opposite direction: women using oral contraceptives had lower levels of $\mathrm{CoQ}_{10}$ compared to women who were not using hormonal contraceptives [33]. This finding is in accordance with other studies that have shown increased oxidative stress in women using oral contraceptives [34]. Based on these findings, we could possibly explain the strong association of the $\mathrm{CoQ}_{10}$ redox state and serum GGT activity found in the women of our study. However, we do not know if our female study subjects were using oral contraceptives or other hormonal therapies. In future research, the hormonal status of female volunteers should be taken into account when 

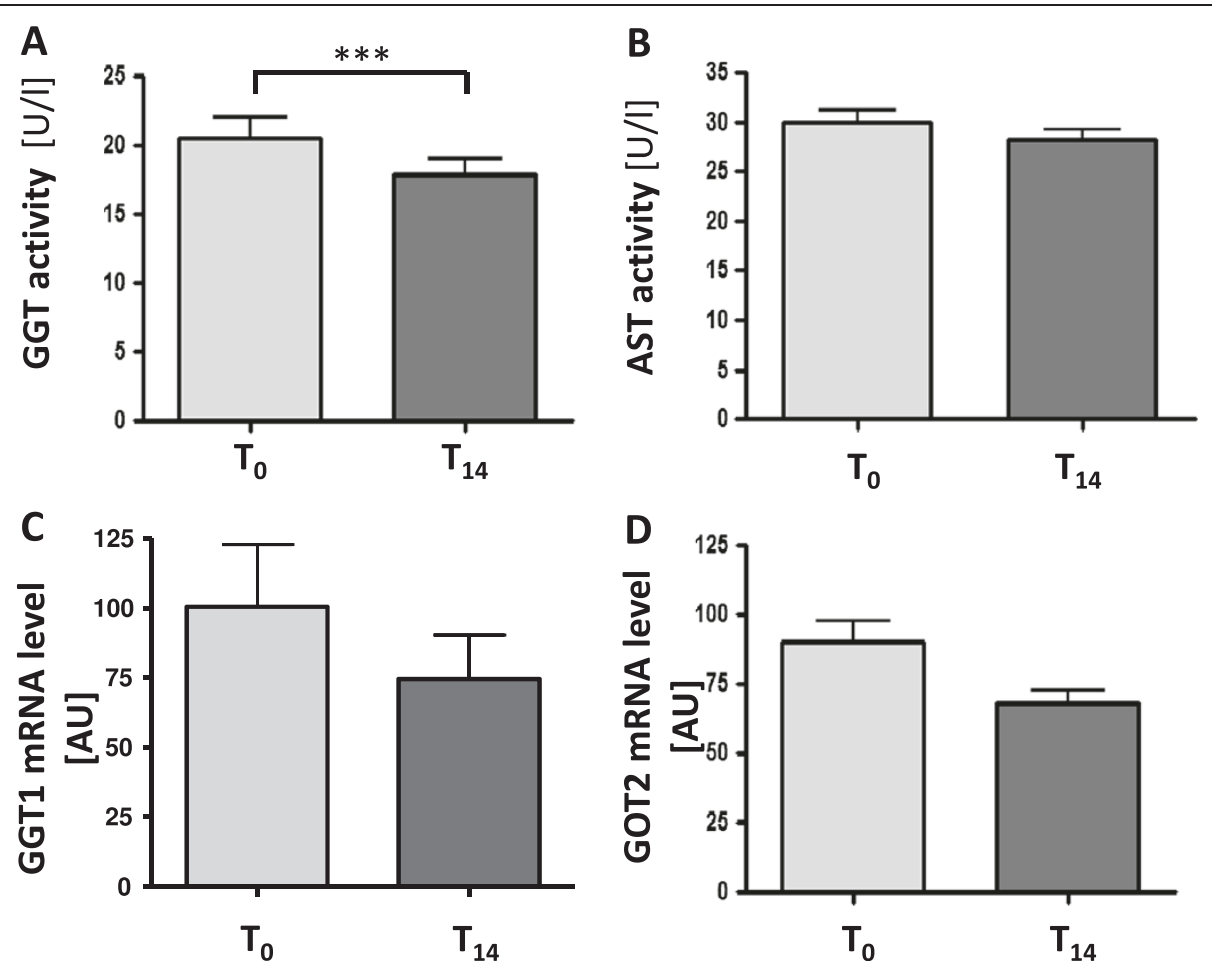

Figure 3 The impact of $\mathrm{Q}_{10} \mathrm{H}_{2}$ supplementation on gamma glutamyltransferase (GGT, A) and GGT1 mRNA levels (B) as well as alanine aminotransferase (AST, C) and GOT2 mRNA levels (D). Data show respective effects before $\left(T_{0}\right)$ and after $\left(T_{14}\right)$ supplementation. Data are calculated from the mean $( \pm S E M)$ of $53(\mathbf{A}+\mathbf{C})$ or rather three $(\mathbf{B}+\mathbf{D})$ volunteers. Bar graphs are presented as the mean $\pm S D,{ }^{* * *} p<0.001$ significant differences between $T_{0}$ and $T_{14}$, paired Student's $t$-test.

investigating the relationship between serum $\mathrm{CoQ}_{10}$ levels and serum GGT activity in women.

Relationship between serum $\mathrm{CoQ}_{10}$ status and serum AST Similar to GGT, AST is associated with oxidative stress and increased all-cause mortality [35,36]. In contrast to GGT, we did not find an association between $\mathrm{CoQ}_{10}$ status and serum AST activity in our study. Therefore, we conclude that the association between GGT and $\mathrm{CoQ}_{10}$ is specific and does not appear to generalize to other liver-related enzymes such as AST.

\section{Supplementation study}

\section{The effect of $Q_{10} H_{2}$ supplementation on serum GGT/AST} activity

$\mathrm{CoQ}_{10}$ is a known modulator of gene expression $[4,5]$ and inflammatory processes [7-9]. Because the reduced form of $\mathrm{CoQ}_{10}$, ubiquinol, is a potent antioxidant that protects lipids, DNA and proteins from oxidative damage [12-14], we examined the effect of $\mathrm{Q}_{10} \mathrm{H}_{2}$ supplementation on both serum GGT and AST activity as potential markers of oxidative stress. Because we revealed an effect of $\mathrm{Q}_{10} \mathrm{H}_{2}$ supplementation on serum GGT activity but not on serum AST activity, we speculate that the effect of $\mathrm{Q}_{10} \mathrm{H}_{2}$ supplementation may be specific to serum GGT activity as a marker of oxidative stress in men. Support for this hypothesis comes from the strong associations found in cohort I between $\operatorname{CoQ}_{10}$ status and GGT activity but not between $\mathrm{CoQ}_{10}$ status and serum AST activity. In contrast, Yuvaraj et al. examined the effect of $\mathrm{CoQ}_{10}$ combined with riboflavin and niacin on serum GGT and serum AST in Tamoxifentreated postmenopausal women with breast cancer [37] and found that the activity of both serum GGT and serum AST decreased in response to exogenous supplementation of $\mathrm{CoQ}_{10}$, niacin and riboflavin. Although Yuvaraj and colleagues used $\mathrm{CoQ}_{10}$ instead of ubiquinol and administered it in combination with niacin and riboflavin, the effect they found on serum AST might be due to a synergistic effect of all three antioxidative co-enzymes. Furthermore, they used a postmenopausal female study sample suffering from breast cancer whereas our study sample was male and healthy. Therefore, hormonal differences as well as disease status should be considered when examining the effects of $\mathrm{Q}_{10} \mathrm{H}_{2}$ supplementation on serum activity levels of liver-related enzymes (i.e., GGT, AST).

Effect of $\mathrm{Q}_{10} \mathrm{H}_{2}$ supplementation on GGT1/GOT2 mRNA level Several studies have shown that oxidative stress, or rather instigators of oxidative stress (i.e., iron), lead to increased GGT mRNA as well as AST mRNA levels [35,38]. Here $\mathrm{Q}_{10} \mathrm{H}_{2}$ supplementation caused a transcriptional down regulation of 
GGT1 mRNA and GOT2 mRNA. The reduction in GGT1 mRNA levels led to a decrease in serum GGT activity and a consequent decline in oxidative stress whereas the transcriptional down regulation of the GOT2 gene caused no decline in serum AST activity.

In summary, $\mathrm{Q}_{10} \mathrm{H}_{2}$ reduced the activity of GGT as a marker of oxidative stress on protein and GGT1 mRNA level in CD14-positive monocytes. Indeed, there is a need for further studies examining the effect of $\mathrm{Q}_{10} \mathrm{H}_{2}$ supplementation on GGT1 mRNA levels in liver tissue. Nevertheless, our findings provide preliminary evidence that there might be an effect of ubiquinol supplementation on serum GGT activity. This effect might be caused by gene expression. Additionally, this supplementation effect seems to be specific to serum GGT activity, as supplementation did not affect the activity of other liver enzymes (i.e., AST).

\section{Conclusions}

There is a strong association between human $\mathrm{CoQ}_{10}$ status and serum GGT activity. However, the strength of this association depends on gender and is more pronounced in men than women. In contrast, female but not male volunteers showed a strong association between the $\mathrm{CoQ}_{10}$ redox state and serum GGT activity. Therefore, further studies are needed to examine the relationship between antioxidative $\mathrm{CoQ}_{10}$ and serum GGT activity as a marker of oxidative stress in both males and females in more detail. Because $\mathrm{Q}_{10} \mathrm{H}_{2}$ supplementation led to a decrease in serum GGT activity as well as GGT1 mRNA levels, we provide preliminary evidence that ubiquinol supplementation might improve oxidative stress on protein and gene expression levels. Further studies are needed to examine this effect in a larger cohort. Additionally, the effect of ubiquinol supplementation on GGT1 mRNA levels should be further examined in organ tissue samples (i.e., liver).

\section{Competing interests}

The authors declare that they have no competing interest regarding the publication of this article.

\section{Authors' contributions}

$\mathrm{SO}$ analyzed the data, interpreted results, and drafted and wrote the manuscript. PN and TM carried out the $\mathrm{CoQ}_{10}$ measurements. GJ, UN and WL were responsible for biobanking in data analysis. FD carried out the gene expression experiments and was responsible for the concept and design of the study, and drafting of the paper. All authors read and critically revised the final manuscript.

\section{Acknowledgements}

We thank all participants of the PopGen-control cohort study for their invaluable contribution to the study. The popgen 2.0 network is supported by a grant from the German Ministry for Education and Research (01EY1103). The whole study was supported by KANEKA Corporation, Japan.

\section{Author details}

${ }^{1}$ Institute of Human Nutrition and Food Science, Division of Molecular Prevention, Christian Albrechts University Kiel, Heinrich-Hecht-Platz 10, 24118 Kiel, Germany. ${ }^{2}$ Children's Hospital of Datteln, University of Witten/Herdecke, Dr.-Friedrich-Steiner Str. 5, 45711 Datteln, Germany. ${ }^{3}$ Institute of Epidemiology and Biobank Popgen, Christian Albrechts University Kiel,
Campus University Hospital Schleswig-Holstein, Niemannsweg 11, Haus 1, 24105 Kiel, Germany. ${ }^{4}$ Institute of Nutrition and Food Science, Rheinische Friedrich Wilhelms University Bonn, Meckenheimer Allee 168, 53115 Bonn, Germany.

Received: 27 February 2014 Accepted: 23 June 2014 Published: 4 July 2014

\section{References}

1. Crane FL: Biochemical functions of coenzyme Q10. J Am Coll Nutr 2001, 20(6):591-598.

2. Lopez-Lluch G, Rodriguez-Aguilera JC, Santos-Ocana C, Navas P: Is coenzyme Q a key factor in aging? Mech Ageing Dev 2010, 131(4):225-235.

3. Bentinger M, Tekle M, Dallner G: Coenzyme Q-biosynthesis and functions. Biochem Biophys Res Commun 2010, 396(1):74-79.

4. Groneberg DA, Kindermann B, Althammer M, Klapper M, Vormann J, Littarru GP, Doring F: Coenzyme Q10 affects expression of genes involved in cell signalling, metabolism and transport in human $\mathrm{CaCo}-2$ cells. Int J Biochem Cell Biol 2005, 37(6):1208-1218.

5. Schmelzer C, Doring F: Identification of LPS-inducible genes downregulated by ubiquinone in human THP-1 monocytes. Biofactors 2010, 36(3):222-228.

6. Lee CK, Pugh TD, Klopp RG, Edwards J, Allison DB, Weindruch R, Prolla TA: The impact of alpha-lipoic acid, coenzyme Q10 and caloric restriction on life span and gene expression patterns in mice. Free Radic Biol Med 2004 36(8):1043-1057.

7. Schmelzer C, Lorenz G, Rimbach G, Doring F: Influence of Coenzyme Q $\{10\}$ on release of pro-inflammatory chemokines in the human monocytic cell line THP-1. Biofactors 2007, 31(3-4):211-217.

8. Schmelzer C, Lorenz G, Rimbach G, Doring F: In Vitro Effects of the Reduced Form of Coenzyme Q(10) on Secretion Levels of TNF-alpha and Chemokines in Response to LPS in the Human Monocytic Cell Line THP-1. J Clin Biochem Nutr 2009, 44(1):62-66.

9. Schmelzer C, Lorenz G, Lindner I, Rimbach G, Niklowitz P, Menke T, Doring F: Effects of Coenzyme Q10 on TNF-alpha secretion in human and murine monocytic cell lines. Biofactors 2007, 31(1):35-41.

10. Barroso MP, Gomez-Diaz C, Villalba JM, Buron MI, Lopez-Lluch G, Navas P: Plasma membrane ubiquinone controls ceramide production and prevents cell death induced by serum withdrawal. J Bioenerg Biomembr 1997, 29(3):259-267.

11. Gonzalez R, Ferrin G, Hidalgo AB, Ranchal I, Lopez-Cillero P, Santos-Gonzalez M, Lopez-Lluch G, Briceno J, Gomez MA, Poyato A, Villalba JM, Navas P, de la Mata M, Muntané J: N-acetylcysteine, coenzyme Q10 and superoxide dismutase mimetic prevent mitochondrial cell dysfunction and cell death induced by d-galactosamine in primary culture of human hepatocytes. Chem Biol Interact 2009, 181(1):95-106.

12. Crane FL, Navas P: The diversity of coenzyme Q function. Mol Aspects Med 1997, 18(Suppl):S1-S6.

13. Ernster L, Dallner $\mathrm{G}$ : Biochemical, physiological and medical aspects of ubiquinone function. Biochim Biophys Acta 1995, 1271(1):195-204.

14. Bentinger M, Brismar K, Dallner G: The antioxidant role of coenzyme Q. Mitochondrion 2007, 7(Suppl):S41-S50.

15. Karp DR, Shimooku K, Lipsky PE: Expression of gamma-glutamyl transpeptidase protects ramos B cells from oxidation-induced cell death. J Biol Chem 2001, 276(6):3798-3804.

16. Hanigan MH, Ricketts WA: Extracellular glutathione is a source of cysteine for cells that express gamma-glutamyl transpeptidase. Biochemistry 1993, 32(24):6302-6306.

17. Courtay C, Heisterkamp N, Siest G, Groffen J: Expression of multiple gamma-glutamyltransferase genes in man. Biochem J 1994, 297(Pt 3):503-508.

18. Teschke R, Brand A, Strohmeyer G: Induction of hepatic microsomal gamma-glutamyltransferase activity following chronic alcohol consumption. Biochem Biophys Res Commun 1977, 75(3):718-724.

19. Brenner H, Rothenbacher D, Arndt V, Schuberth S, Fraisse E, Fliedner TM: Distribution, determinants, and prognostic value of gammaglutamyltransferase for all-cause mortality in a cohort of construction workers from southern Germany. Prev Med 1997, 26(3):305-310.

20. Lee DH, Jacobs DR Jr, Gross M, Kiefe Cl, Roseman J, Lewis CE, Steffes M: Gamma-glutamyltransferase is a predictor of incident diabetes and hypertension: the Coronary Artery Risk Development in Young Adults (CARDIA) Study. Clin Chem 2003, 49(8):1358-1366. 
21. Jousilahti $P$, Rastenyte $D$, Tuomilehto J: Serum gamma-glutamyl transferase, self-reported alcohol drinking, and the risk of stroke. Stroke 2000, 31(8):1851-1855

22. Perry IJ, Wannamethee SG, Shaper AG: Prospective study of serum gamma-glutamyltransferase and risk of NIDDM. Diabetes Care 1998, 21(5):732-737.

23. Lee $D H$, Blomhoff $R$, Jacobs $D R$ Jr: Is serum gamma glutamyltransferase a marker of oxidative stress? Free Radic Res 2004, 38(6):535-539.

24. Lim JS, Yang JH, Chun BY, Kam S, Jacobs DR Jr, Lee DH: Is serum gammaglutamyltransferase inversely associated with serum antioxidants as a marker of oxidative stress? Free Radic Biol Med 2004, 37(7):1018-1023.

25. Lee DH, Lim JS, Yang JH, Ha MH, Jacobs DR Jr: Serum gammaglutamyltransferase within its normal range predicts a chronic elevation of alanine aminotransferase: a four year follow-up study. Free Radic Res 2005, 39(6):589-593.

26. Nothlings U, Krawczak M: PopGen. A population-based biobank with prospective follow-up of a control group. Bundesgesundheitsblatt Gesundheitsforschung Gesundheitsschutz 2012, 55(6-7):831-835.

27. Schmelzer C, Niklowitz P, Okun JG, Haas D, Menke T, Doring F: Ubiquinolinduced gene expression signatures are translated into altered parameters of erythropoiesis and reduced low density lipoprotein cholesterol levels in humans. IUBMB Life 2011, 63(1):42-48.

28. Menke T, Niklowitz P, Adam S, Weber M, Schluter B, Andler W. Simultaneous detection of ubiquinol-10, ubiquinone-10, and tocopherols in human plasma microsamples and macrosamples as a marker of oxidative damage in neonates and infants. Anal Biochem 2000, 282(2):209-217.

29. Lee DH, Gross MD, Jacobs DR Jr: Association of serum carotenoids and tocopherols with gamma-glutamyltransferase: the Cardiovascular Risk Development in Young Adults (CARDIA) Study. Clin Chem 2004, 50(3):582-588.

30. Kaikkonen J, Nyyssonen K, Tuomainen TP, Ristonmaa U, Salonen JT: Determinants of plasma coenzyme Q10 in humans. FEBS Lett 1999, 443(2):163-166.

31. Miles MV, Horn PS, Morrison JA, Tang PH, DeGrauw T, Pesce AJ: Plasma coenzyme Q10 reference intervals, but not redox status, are affected by gender and race in self-reported healthy adults. Clin Chim Acta 2003, 332(1-2):123-132.

32. Nilssen O, Forde OH, Brenn T: The Tromso Study. Distribution and population determinants of gamma-glutamyltransferase. Am J Epidemiol 1990, 132(2):318-326.

33. Palan PR, Magneson AT, Castillo M, Dunne J, Mikhail MS: Effects of menstrual cycle and oral contraceptive use on serum levels of lipidsoluble antioxidants. Am J Obstet Gynecol 2006, 194(5):e35-e38.

34. Chen JT, Kotani K: Oral contraceptive therapy increases oxidative stress in pre-menopausal women. Int J Prev Med 2012, 3(12):893-896.

35. Josekutty J, labal J, Iwawaki T, Kohno K, Hussain MM: Microsomal triglyceride transfer protein inhibition induces endoplasmic reticulum stress and increases gene transcription via Ire1alpha/cJun to enhance plasma ALT/AST. J Biol Chem 2013, 288(20):14372-14383.

36. Koehler EM, Sanna D, Hansen BE, van Rooij FJ, Heeringa J, Hofman A, Tiemeier $\mathrm{H}$, Stricker BH, Schouten JN, Janssen $\mathrm{HL}$ : Serum liver enzymes are associated with all-cause mortality in an elderly population. Liver Int 2014, 34(2):296-304.

37. Yuvaraj S, Premkumar VG, Shanthi P, Vijayasarathy K, Gangadaran SG, Sachdanandam P: Effect of Coenzyme Q(10), Riboflavin and Niacin on Tamoxifen treated postmenopausal breast cancer women with special reference to blood chemistry profiles. Breast Cancer Res Treat 2009, 114(2):377-384.

38. Brown KE, Kinter MT, Oberley TD, Freeman ML, Frierson HF, Ridnour LA, Tao Y, Oberley LW, Spitz DR: Enhanced gamma-glutamyl transpeptidase expression and selective loss of CuZn superoxide dismutase in hepatic iron overload. Free Radic Biol Med 1998, 24(4):545-555.

doi:10.1186/1756-0500-7-427

Cite this article as: Onur et al: Ubiquinol reduces gamma

glutamyltransferase as a marker of oxidative stress in humans. BMC Research Notes 2014 7:427.

\section{Submit your next manuscript to BioMed Central and take full advantage of:}

- Convenient online submission

- Thorough peer review

- No space constraints or color figure charges

- Immediate publication on acceptance

- Inclusion in PubMed, CAS, Scopus and Google Scholar

- Research which is freely available for redistribution
C Biomed Central 